\title{
Friction on Ice: How Temperature, Pressure, and Speed Control the Slipperiness of Ice
}

\author{
Rinse W. Liefferink $\odot,{ }^{1, *}$ Feng-Chun Hsia $\odot,{ }^{1,2}$ Bart Weber®, ${ }^{1,2}$ and Daniel Bonn ${ }^{1}$ \\ ${ }^{1}$ Institute of Physics, University of Amsterdam, Science Park 904, 1098 XH Amsterdam, Netherlands \\ ${ }^{2}$ Advanced Research Center for Nanolithography, Science Park 106, 1098 XG Amsterdam, Netherlands
}

(Received 17 July 2020; revised 30 October 2020; accepted 9 December 2020; published 8 February 2021)

\begin{abstract}
We present sphere-on-ice friction experiments as a function of temperature, contact pressure, and speed. At temperatures well below the melting point, friction is strongly temperature dependent and follows an Arrhenius behavior, which we interpret as resulting from the thermally activated diffusive motion of surface ice molecules. We find that this motion is hindered when the contact pressure is increased; in this case, the friction increases exponentially, and the slipperiness of the ice disappears. Close to the melting point, the ice surface is plastically deformed due to the pressure exerted by the slider, a process depending on the slider geometry and penetration hardness of the ice. The ice penetration hardness is shown to increase approximately linearly with decreasing temperature and sublinearly with indentation speed. We show that the latter results in a nonmonotonic dependence of the ploughing force on sliding speed. Our results thus clarify the complex dependence of ice friction on temperature, contact pressure, and speed.
\end{abstract}

DOI: 10.1103/PhysRevX.11.011025

Subject Areas: Materials Science, Soft Matter

\section{INTRODUCTION}

It is commonly believed that ice is slippery due to the presence of a layer of liquidlike water on the surface of ice which acts as a lubricant. However, the origin of this layer and the resulting lubrication have been debated for more than 150 years [1-13]. The lubricating layer that allows ice skating has been attributed to pressure-induced [2] or friction-induced [3] melting of the ice surface and to the presence of a premelted layer of ice [4]. More recently, authors have suggested that the diffusion of water molecules over the ice surface is responsible for low ice friction at high temperatures and low sliding speeds [14]. Furthermore, reciprocated ball-on-ice friction measurements performed using a tuning fork have recently revealed that — during reciprocated sliding [15] on ice-a lubricating, viscous mixture of liquid water and ice particles dominates the frictional behavior [16]. In the context of each of these proposed lubrication mechanisms, the local contact pressure exerted at the slider-on-ice interface is a crucial parameter that remains ill understood.

In this work, we therefore take a closer look at this local contact pressure and show that (i) the hardness of ice displays a strong temperature and strain rate dependence that, close to melting, leads to rich ploughing behavior that is controlled by

\footnotetext{
*r.w.liefferink@uva.nl, he/him/his
}

Published by the American Physical Society under the terms of the Creative Commons Attribution 4.0 International license. Further distribution of this work must maintain attribution to the author(s) and the published article's title, journal citation, and DOI. the temperature, sliding speed, surface topography, and surface geometry; (ii) friction on ice increases exponentially with the local contact pressure, suggesting that this pressure frustrates the mobility of the lubricating layer; (iii) in the water-immersed sphere-on-artificial ice experiment, we observe the onset of mixed lubrication at sliding speeds above $1 \mathrm{~m} / \mathrm{s}$, indicating that most of our ball-on-ice experiments are likely boundary lubricated.

\section{METHODS}

To investigate the slipperiness of ice, we move a spherical slider over an ice surface. The slider is clamped to a commercial rheometer (Anton Paar, DSR 502), at a distance of $5 \mathrm{~mm}$ from the rotation axis. The imposed rotation speed and the measured torque can thus be converted into a sliding velocity and a friction force, respectively. We vary the sliding speed from $10^{-6}$ up to $10^{-1} \mathrm{~m} / \mathrm{s}$ and measure the normal force $N$ and friction force $F$ exerted at the slider-on-ice interface. The ratio of these two forces gives the friction coefficient $\mu$. The setup is thermally isolated and cooled with liquid nitrogen (temperature $T$ between $-110^{\circ} \mathrm{C}$ and $-15^{\circ} \mathrm{C}$ ) or a coolant liquid ( $T$ between $-15^{\circ} \mathrm{C}$ and $0{ }^{\circ} \mathrm{C}$ ). A flat ice surface is established by repeatedly adding a small amount of demineralized water on top of the already-frozen water. As the added water initially melts the top surface of the ice, a smooth polycrystalline ice surface is formed. The temperature is measured with an embedded thermocouple close to the surface and controlled with the flow rate of the cooling liquid.

As sliders, we use silicon-carbide spheres (from Latech), soda-lime glass spheres (from SiLibeads), a sapphire sphere 
TABLE I. Mechanical and geometrical details of the sliders used in the friction experiments.

\begin{tabular}{lccrrr}
\hline \hline Material & $\begin{array}{c}\text { Radius } \\
(\mathrm{mm})\end{array}$ & $\begin{array}{c}\text { Roughness } \\
(\mathrm{nm})\end{array}$ & $\begin{array}{c}\text { Hardness } \\
(\mathrm{GPa})\end{array}$ & $\begin{array}{c}\text { Elastic } \\
\text { modulus (GPa) }\end{array}$ & $\begin{array}{c}\text { Poisson's } \\
\text { ratio (-) }\end{array}$ \\
\hline Silicon carbide & $0.75,6.00$ & 140 & 27.0 & 410 & 0.14 \\
Soda-lime glass & 1.84 & $98,222,575,3077$ & 5.7 & 65 & 0.22 \\
Sapphire & 1.59 & 28 & 21.6 & 2 & 0.29 \\
Stainless steel & $\approx 22$ & 856 & 2.0 & 200 & 0.28 \\
\hline \hline
\end{tabular}

(from Edmund Optics), and a model ice skate (stainless steel); see Table I for details. The microscopic surface topography of the balls is measured by laser-scanning confocal microscopy (Keyence VK-X1000) over an area of 208 by $208 \mu \mathrm{m}$ with a lateral resolution of $138 \mathrm{~nm} / \mathrm{pixel}$ and $20 \mathrm{~nm}$ resolution in the height direction. We do not observe significant changes in the surface topography of the sliders after the friction experiments and therefore conclude that the sliders do not wear during the friction experiments. The surface roughness values listed in Table I refer to the root-mean-square (rms) height variation $S_{q}$ from the profilometry experiments, after subtracting the curvature of the spheres. As the surface roughness is known to influence the local contact pressure at interfaces, we vary the surface roughness of the soda-lime sliders by inserting them one at a time in a container with sandpaper walls and shaking them for 2 hours to obtain a roughened surface. By varying the sandpaper grits (P3000, P2500, and P150), the resulting surface topography can be controlled $\left(S_{q}=222\right.$, 575, and $3077 \mathrm{~nm}$, respectively). To approximate an iceskate-on-ice interface in the experiments, we cut a $5-\mathrm{mm}$ piece out of an actual ice skate. This model skate has a width of $1.67 \mathrm{~mm}$ and a radius of curvature (along the length) of $22 \mathrm{~m}$. The front and back edges of the model skate are rounded off.

To quantify the penetration hardness $P_{h}$ of the ice, we perform indentation experiments in which a stainless-steel sphere with radius $R=1.6 \mathrm{~mm}$ is pushed onto the ice by a tensile tester machine (ZwickRoell Z2.5, with a Z6FD1 load cell) at various temperatures and preset indentation speeds $v_{\text {ind }}$, resulting in plastic deformation of the ice. The indentation depth $\delta$ and indentation force $N$ are measured up to a maximum load of $80 \mathrm{~N}$; see the Appendix A. To quantify the penetration hardness, we divide the penetration force by the projected area $A_{c}=\pi r^{2}$ on which it acts [see inset of Fig. 2(a)]. Since $r^{2}=2 R \delta$ for $\delta \ll R$, we can write $P_{h}=(N / 2 \pi R \delta)$, which is averaged over the measured indentation range from 25 to $75 \mathrm{~N}$.

Based on the mechanical properties of the slider and the ice and the surface topography of the slider, we use the Tribology Simulator (from Tribonet [17]) to solve the elastic-plastic contact equations through a numerical model. Here, we make use that the ice surface has an elastic modulus and Poisson's ratio of $0.75 \mathrm{GPa}$ and 0.33 , respectively [14]. The hardness is measured independently as a function of temperature and velocity. As the surface roughness of ice is relatively low $\left[S_{q}=61 \mathrm{~nm}\right.$, calculated for the measured surface topography of Fig. 3(b), bottom] and without long-range curvature, the surface topography of the sliders dominates the contact calculations. Including the ice topography raises the contact pressure only $4 \%$, and, therefore, the surface topography of ice can be neglected.

\section{RESULTS}

\section{A. Temperature dependence}

Figure 1 shows the friction coefficient $\mu$ as a function of temperature for the two types of $\mathrm{SiC}$ spheres and the model

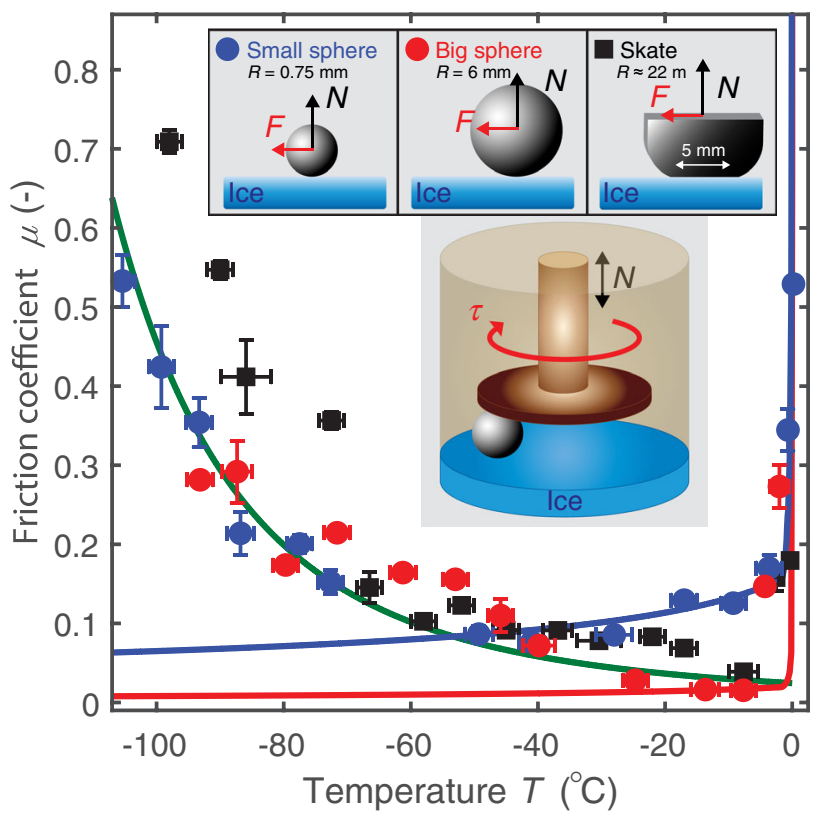

FIG. 1. Friction coefficient $\mu$ as a function of the temperature $T$ for various sliders on ice. At a constant sliding speed $v_{s}$ of $0.38 \mathrm{~mm} / \mathrm{s}$, a small sphere (radius $R=0.75 \mathrm{~mm}$, blue circles), a big sphere $(R=6 \mathrm{~mm}$, red circles), and a model ice skate ( $R \approx 22 \mathrm{~m}$, width $1.67 \mathrm{~m}$, and length $5 \mathrm{~mm}$; black squares) are slid over an ice surface at a normal force of 2.5 N. Far from the melting point, the friction coefficient follows an Arrhenius temperature dependence with an activation energy of $\Delta E=11.5 \mathrm{~kJ} / \mathrm{mol}$. Close to the melting point, the friction coefficient increases rapidly as the sliders start to plough through the ice. The error bars represent the standard deviation. Inset: schematic illustration of the experimental setup. A slider is clamped to a commercial rheometer where, for an imposed rotation speed, the torque $\tau$ and normal force $N$ are monitored. 
skate. In agreement with earlier measurements [14], we find that the temperature dependence of the friction coefficient can be captured by an Arrhenius-type equation:

$$
\mu=c e^{\Delta E / k_{B} T},
$$

with fitting parameter $c=1.5 \times 10^{-4}$ and activation energy $\Delta E=11.5 \mathrm{~kJ} / \mathrm{mol}$. As reported in Ref. [14], this activation energy matches the activation energy for ice-surface diffusion $[18,19]$, suggesting that the diffusion of water molecules over the ice surface plays an important role in ice friction. For temperatures above $-20^{\circ} \mathrm{C}$, the spherical slider displays a friction coefficient that is higher than the friction coefficient predicted by the Arrhenius equation and increases with temperature up to the melting point of ice. This increase in friction with temperature is the result of ploughing friction; the slider plastically indents the ice in the normal direction and consequently ploughs through the surface in the lateral direction [20]. The pressure that the slider exerts on the ice surface controls the magnitude of the ploughing force. To further investigate the influence of contact pressure and quantify the ploughing force, we vary the contact pressure exerted by the slider by varying its curvature.

(a)

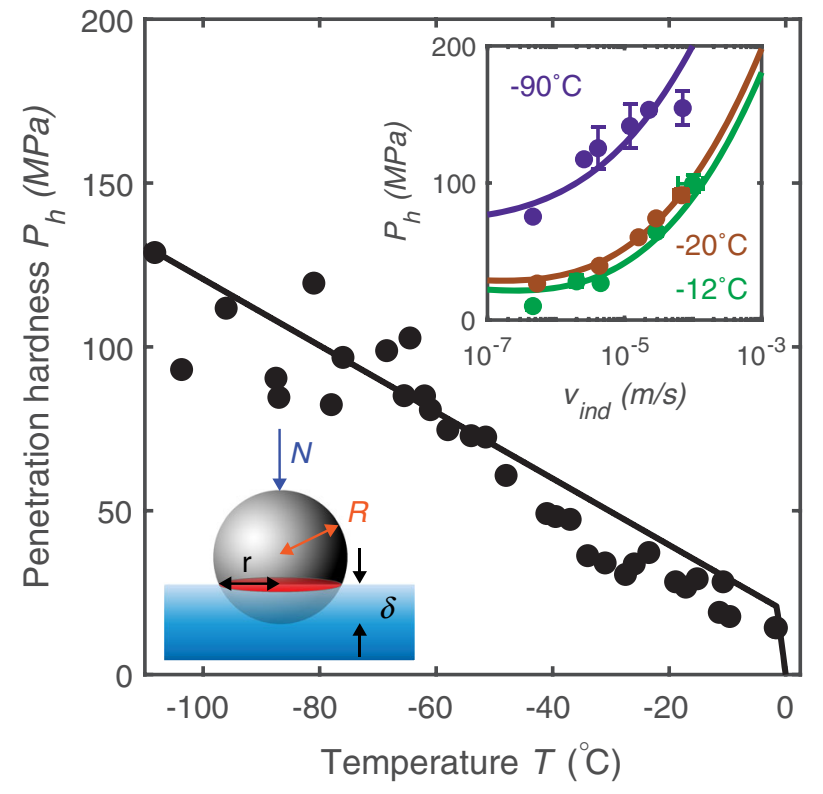

\section{B. Ploughing}

The ploughing force can be calculated by considering plastic indentation in the normal direction, which occurs when the contact pressure exceeds the penetration hardness $P_{h}$ of the ice. This penetration hardness decreases linearly with increasing temperature [see Fig. 2(a)] up to $-1.5^{\circ} \mathrm{C}$ when pressure melting sharply decreases the hardness. Now, during sliding, the sphere plastically indents the ice with a depth $\delta$ until the contact area $A_{c}$ has increased enough to support the set normal force $N$ [see inset of Fig. 2(b) and Appendix B]. This indentation results in scratching laterally into the ice with a ploughing area $A_{P}$ and a ploughing force $F_{P}$, which, consequently, results in a ploughing friction coefficient [21,22]:

$$
\mu_{P}=\frac{A_{P} P_{h}(T)}{N}
$$

Based on the geometry shown in Fig. 2(b), this can be written as [14,23]

$$
\mu_{P}=\frac{4 \sqrt{2}}{3 \pi^{3 / 2} R} \sqrt{\frac{N}{P_{h}(T)}} .
$$

(b)

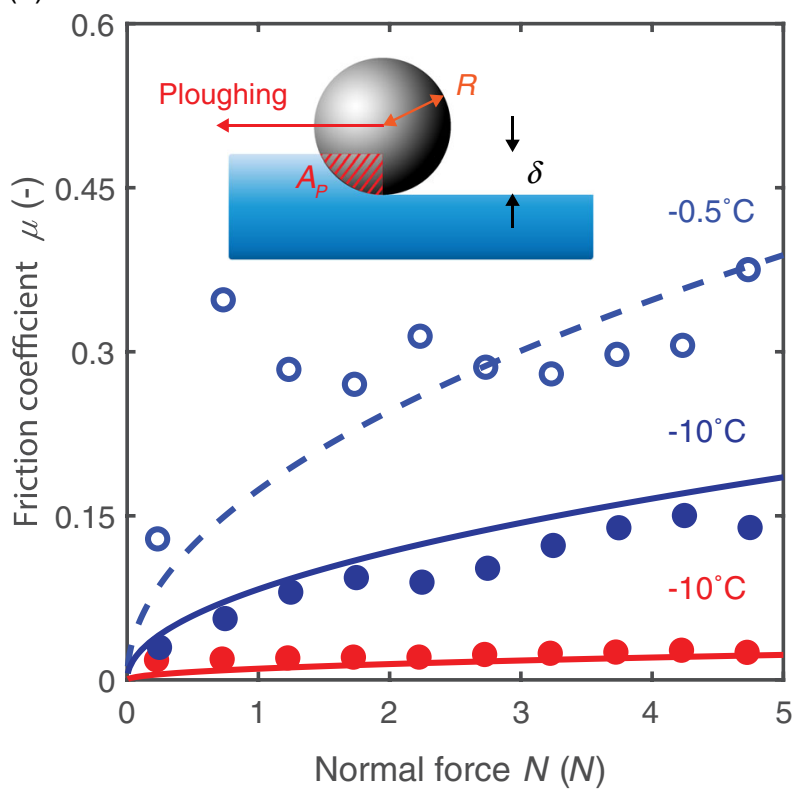

FIG. 2. (a) Penetration hardness $P_{h}$ of ice as a function of temperature, obtained from indentation experiments at a speed of $v_{\text {ind }}=3.8 \mu \mathrm{m} / \mathrm{s}$. Indentation is performed with a sphere pushed into the ice at various temperatures; see inset (left bottom) for a schematic illustration. The indentation depth $\delta$ and force $N$ are monitored to calculate the $P_{h}$. The error bars, defined by the standard deviation in the penetration hardness, are smaller than the symbols used. A linear decrease of $P_{h}$ with temperature is found (black line) up to $-1.5^{\circ} \mathrm{C}$ when pressure-induced melting sharply decreases the hardness. Upper inset: $P_{h}$ versus $v_{\text {ind }}$ for various temperatures. (b) Friction coefficient $\mu$ as a function of the normal force $N$ for a small (radius $R=0.75 \mathrm{~mm}$, blue open and filled circles) and large ( $R=6.00 \mathrm{~mm}$, red filled circles) $\mathrm{SiC}$ spherical slider. The ploughing model [lines, Eq. (3)] matches the observed friction coefficient. Inset: schematic illustration of ploughing in ice. The spherical slider of radius $R$ indents the ice in the normal direction with a depth $\delta$ and cross section $A_{P}$. 
Figure 2(b) indeed confirms that both a decrease of the radius (red-filled compared to blue-filled circles) and a decrease of hardness (blue-filled compared to blue open circles) result in an increase in ploughing force; the ploughing model captures the experimentally measured variations in the friction coefficient without adjustable parameters. This result is also reflected in the different amounts of ploughing for different spherical sliders observed in Fig. 1.

These insights into the phenomenon of ploughing translate to the practice of ice skating. During ice skating, low sliding friction is desired to achieve a high sliding speed, but, simultaneously, high friction is required to enable changing the sliding direction. Therefore, the blades of ice skates have a large radius of curvature in the sliding direction, $R=3-22 \mathrm{~m}$, and sharp edges with a flat or even negative radius of curvature along the width [24]. A low coefficient of friction can be expected if the skate is perfectly aligned with the ice surface, but if the skate is tilted, a quick increase of the friction coefficient is found $[6,25]$. A tilt of the skate results in (deeper) indentation of the ice and therefore an increase of the friction, particularly in the direction perpendicular to the length of the skate because sliding in this direction involves a larger ploughing area. This larger ploughing force gives the skater the opportunity to push forward and make turns. In Fig. 1, the friction coefficient of a $5-\mathrm{mm}$ section of a long skate blade is measured as a function of temperature (black squares). A large decrease of the friction coefficient with increasing temperature can be found up to $-8^{\circ} \mathrm{C}$, whereafter the friction increases again due to ploughing. The minimum friction for the model ice skate is found for $T=-7.7 \pm 2.3^{\circ} \mathrm{C}$ with $\mu=0.039 \pm 0.003$.

Therefore, sliding on ice is largely temperature dependent and can be captured with an Arrhenius-type equation in the elastic regime. Close to the melting point, when the slider plastically indents the ice surface, the friction coefficient increases due to ploughing, where the magnitude of ploughing is set by (a) the hardness of the ice, (b) the slider geometry (radius of curvature), and (c) the exerted normal force.

\section{Local contact pressure}

Conventional liquid lubrication is essentially a competition between squeeze flow and sliding (or rolling) induced entrainment of the lubricant. The squeeze flow is driven by an externally applied normal force, which sets the local pressure experienced by the lubricant. To investigate the influence of this local contact pressure on the slider-on-ice friction, we vary the microscopic surface topography of the spherical slider; the sharper the roughness peaks on the slider, the higher the local contact pressure [26]. In Fig. 3(a), we report the friction force as a function of normal force, measured for glass spheres with surface roughnesses $S_{q}$ from $98 \mathrm{~nm}$ to $3077 \mathrm{~nm}$. We find that the smoothest sphere displays a friction coefficient that is equal to that reported in Fig. 1 at the corresponding temperature, here set to $-50^{\circ} \mathrm{C}$, and described by the Arrhenius equation, Eq. (1). The spheres with higher surface roughness, and therefore a higher contact pressure, display a significantly higher friction coefficient. For $T=-30^{\circ} \mathrm{C}$, $-70{ }^{\circ} \mathrm{C}$, and $-90^{\circ} \mathrm{C}$, a qualitatively similar result is found.

To quantify the contact pressure $P_{c}$, we perform contact calculations in which the mechanical properties of the slider and the ice, and the measured surface topography of the slider form the input. The interfacial gap, at each of the in-plane coordinates defined by the topography, forms the output of the calculation for a given normal force. Those locations at which the interfacial gap is zero form the area of real contact where, in addition, the local contact pressure is quantified. In Fig. 3(c), we plot the measured surface topography and the calculated area of real contact for glass spheres with increasing roughness at a temperature of $-50^{\circ} \mathrm{C}$. We find that the relatively smooth spheres $\left[S_{q}=98 \mathrm{~nm}\right.$; Fig. 3(c), left panel] primarily deform the ice elastically at an average contact pressure of $35 \mathrm{MPa}$. This result is independent of temperature because the elastic modulus of the ice (and the slider) does not change significantly with temperature. The situation is different for balls with a relatively high surface roughness $\left[S_{q}=3077 \mathrm{~nm}\right.$ or higher; Fig. 3(c), right panel]. As the surface roughness is increased above this level, the calculated average contact pressure increases up to $85 \mathrm{MPa}$, which equals the hardness of the ice, indicating that plasticity plays an important role in the contact formation for these rougher spheres. The hardness of the ice decreases linearly with temperature and limits the maximal contact pressure; the contact pressure in this regime of plastic deformation varies from $130 \mathrm{MPa}$ at $-90^{\circ} \mathrm{C}$ to $70 \mathrm{MPa}$ at $-30^{\circ} \mathrm{C}$ (see Appendix C). Note that the contact pressure in both the plastic and the elastic regime is almost independent of the normal force because the area of real contact increases linearly with normal force; see Appendix C.

Spheres that deform the ice plastically will plough through the ice when tangentially loaded. In Fig. 3(b), top, we plot the ploughing track that was left on the ice after a sphere with high roughness, $S_{q}=3077 \mathrm{~nm}$, slid over the ice surface with a normal force of $N=0.21 \mathrm{~N}$ and a speed of $v \approx 5 \mathrm{~mm} / \mathrm{s}$. In contrast, spheres with low roughness $S_{q}=98 \mathrm{~nm}$ do not leave visible damage after sliding on the ice [Fig. 3(b), bottom], as expected based on the fact that the calculated average contact pressure for these balls in contact with ice is smaller than the penetration hardness of the ice. Although the plastification during sliding increases the friction force, it only provides a small contribution. The maximum friction due to ploughing, represented by the arrow in Fig. 3(a), can only explain $30 \%$ of the observed variation in friction with roughness (see Appendix D). Therefore, we measure and calculate the interfacial shear stress $\sigma_{s}$, which is the friction force 


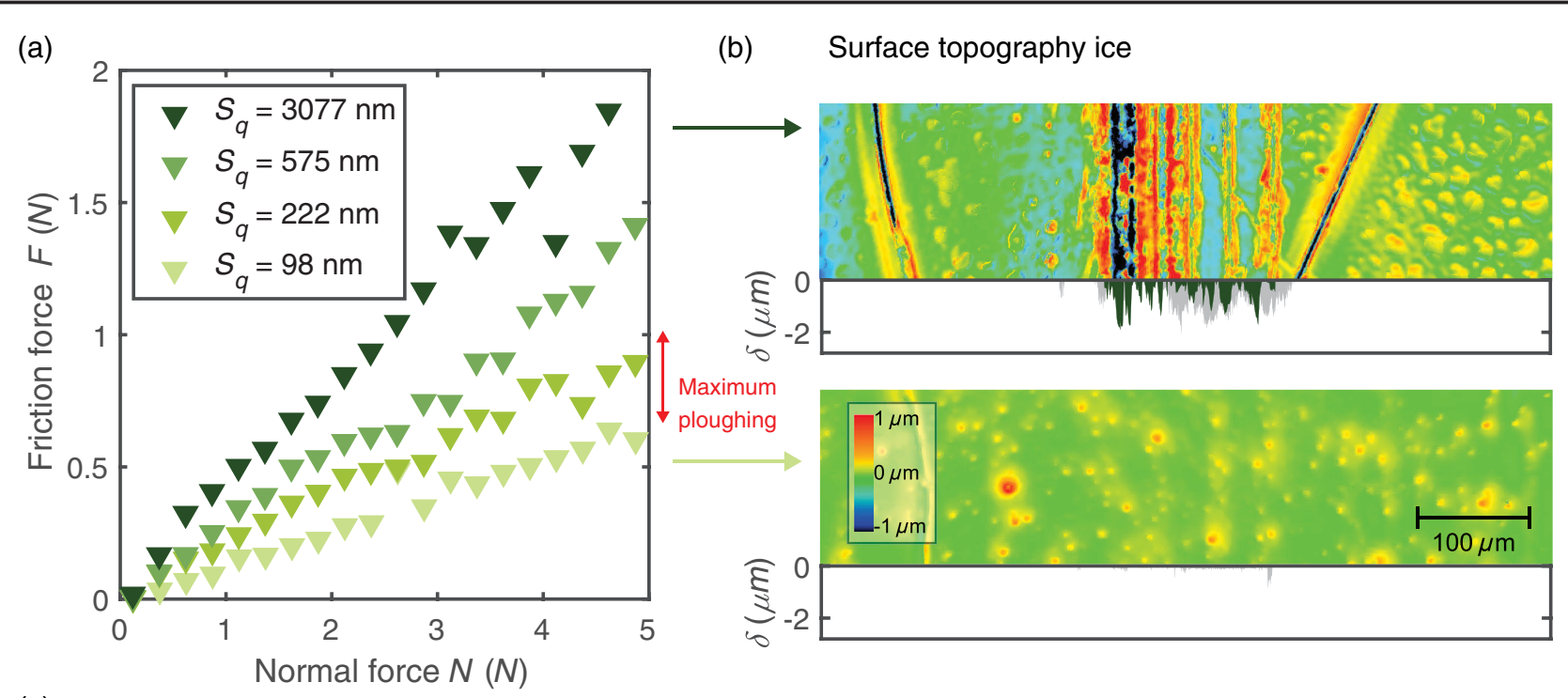

(c)

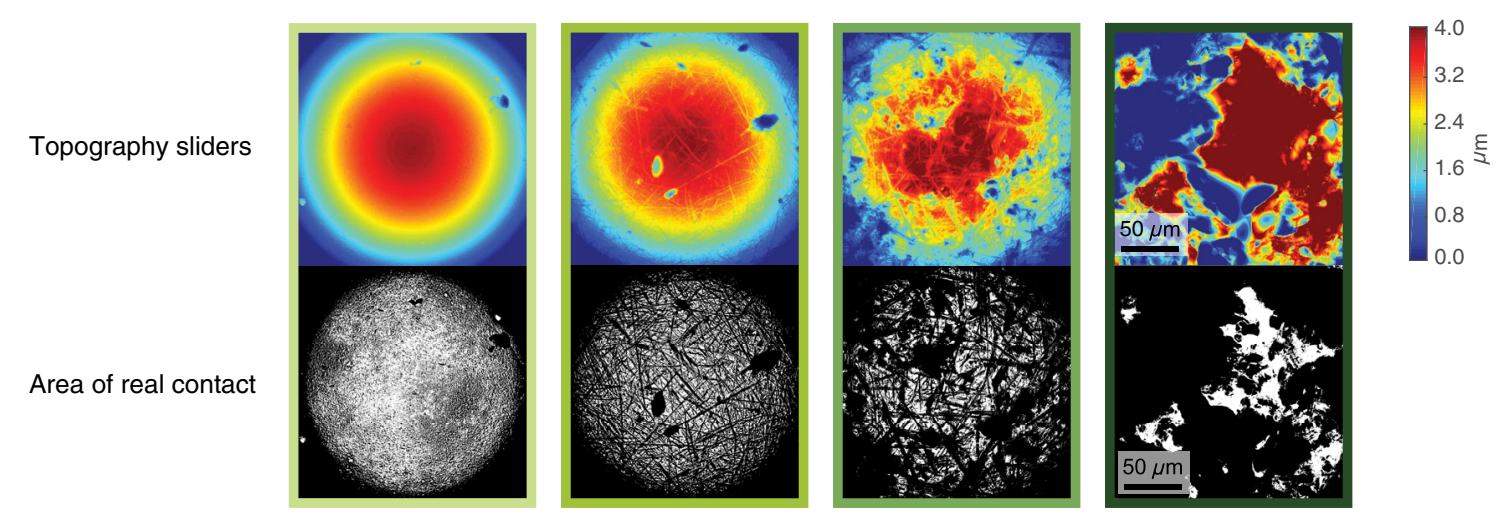

FIG. 3. (a) Friction force as a function of normal force measured for glass spheres with surface roughness $S_{q}$ of $98,222,575$, and $3077 \mathrm{~nm}$ at a temperature of $-50^{\circ} \mathrm{C}$ and sliding speed of $0.38 \mathrm{~mm} / \mathrm{s}$. The smoothest sphere displays a friction equal to that reported in Fig. 1, which can be described by the Arrhenius equation [Eq. (1)]. For increasing surface roughness, a higher friction force is measured. (b) Surface topography and corresponding ploughing depth $\delta$ in the ice after a sphere with the highest (top) and lowest (bottom) roughness slides over it at a normal force of $0.21 \mathrm{~N}$. The calculated plastic indentation depth $\delta$ for a normal force of $0.21 \mathrm{~N}$ is added in light gray in the insets. (c) Surface topography (top) and calculated area of real contact (bottom) for the same glass spheres at $T=-50^{\circ} \mathrm{C}$ at a normal force of $0.5 \mathrm{~N}$. A transition from primarily elastic contact for a smooth slider towards elastic-plastic contact for a rough slider can be observed.

divided by the area of real contact at which the friction force is generated.

Perhaps somewhat surprisingly, in the elastic regime, $\sigma_{s}$ increases exponentially for increasing contact pressure $P_{c}$; see inset of Fig. 4 for $-50{ }^{\circ} \mathrm{C}$. Qualitatively similar results are found for $T=-30^{\circ} \mathrm{C},-70^{\circ} \mathrm{C}$, and $-90^{\circ} \mathrm{C}$; the lowest roughness has a shear stress expected based on the Arrhenius behavior, while increasing the contact pressure up to the penetration hardness of the ice results in an exponential increase of the shear stress. These results are summarized in Fig. 4 (triangles), where the contact pressure and shear stress are normalized by, respectively, the penetration hardness of the ice $P_{h}$ and the Arrhenius temperature dependence of the friction coefficient $e^{\Delta E / k_{B} T}$. The exponential increase of interfacial shear stress with pressure is also known as piezo-viscosity; the viscosity of a confined lubricant increases exponentially with the mechanical pressure $[27,28]$. The viscosity $\eta$ is then described empirically as

$$
\eta=\eta_{\mathrm{ref}} e^{\frac{P_{c}}{\beta}}
$$

Here, the pressure-viscosity parameter $\beta$ sets the increase of the viscosity with the exerted pressure starting from the unconfined viscosity $\eta_{\text {ref }}$. For sliding friction on ice, a qualitatively similar process occurs; the shear stress increases when the contact pressure on the mobile layer is increased. From Fig. 4, we can model the shear stress as

$$
\sigma_{s}=\sigma_{0} e^{\frac{\Delta E}{k_{B} T}} e^{\frac{P_{c}}{P_{h}(T)}}
$$

with $\sigma_{0}=2.1 \mathrm{kPa}$ and $b=3.4$. The shear stress is set by the mobility of the ice surface, which is decreased, or 


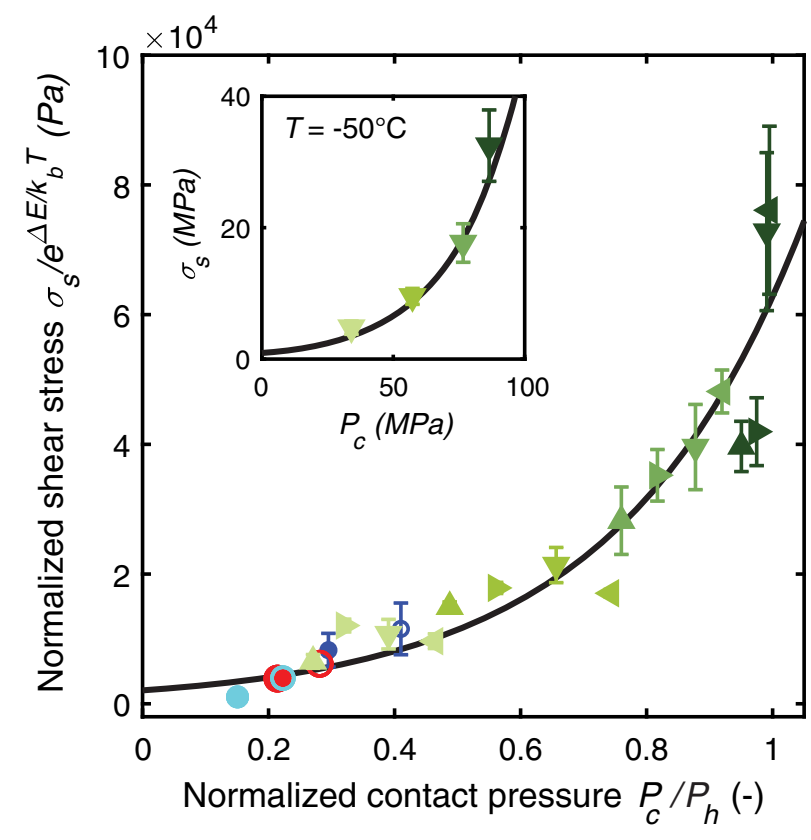

FIG. 4. Normalized shear stress $\sigma_{s} / e^{\Delta E / k_{B} T}$ as a function of the normalized contact pressure $P_{c} / P_{h}$ for various sliders, surface roughnesses, and temperatures at a sliding speed of $0.38 \mathrm{~mm} / \mathrm{s}$. The solid line is a fit using Eq. (5). Triangles from light green to dark green correspond to glass spheres with a surface roughness $S_{q}$ of $98,222,575$, and $3077 \mathrm{~nm}$, where upward, right, down, and left-pointing triangles are measurements at $T=-90{ }^{\circ} \mathrm{C},-70{ }^{\circ} \mathrm{C}$, $-50^{\circ} \mathrm{C}$, and $-30^{\circ} \mathrm{C}$, respectively. The blue, red, and cyan circles correspond to, respectively, a small $\mathrm{SiC}(R=0.75 \mathrm{~mm})$, a large $\mathrm{SiC}(R=6 \mathrm{~mm})$, and a sapphire sphere $(R=1.59 \mathrm{~mm})$ at $T=$ $-90{ }^{\circ} \mathrm{C}$ for closed and $-50{ }^{\circ} \mathrm{C}$ for open markers. The error bars represent the standard deviation in the measured friction force. Inset: shear stress as a function of the contact pressure for various glass sliders with increasing surface roughness at $T=-50{ }^{\circ} \mathrm{C}$ and a sliding speed of $0.38 \mathrm{~mm} / \mathrm{s}$.

"frustrated," for increasing contact pressures up to the plastic limit. The piezo-viscous effect on the shear stress could be interpreted as a result of confinement; the surface water molecules become more strongly confined at the slider-onice interface with increasing contact pressure. For nanoconfined water molecules, it has been observed that the (apparent) viscosity increases when the gap size is decreased to less than a nanometer [29-31]. Additionally, we include in Fig. 4 the measurements for the small $(0.75$-mm radius $)$ and large (6.00-mm radius) $\mathrm{SiC}$ spheres and a low-roughness sapphire sphere (1.59-mm radius). For these three spheres, the calculated shear stress and contact pressure based on the measured friction force and surface topography $\left(T=-50{ }^{\circ} \mathrm{C}\right.$ and $-90^{\circ} \mathrm{C}$; see Appendix C) match well with the fit made for the glass spheres. A "slippery" state can therefore only be reached when the exerted contact pressure is sufficiently small, which is the case for a slider (or skate) with a small surface roughness and a large curvature.

Overall, we observe an increase of the friction force when the local contact pressure is increased. Next to, perhaps, a minor contribution due to ploughing, the increase of friction can be explained by a piezo-viscous effect; for increasing contact pressure up to the plastic limit, the shear stress increases exponentially.

\section{Sliding speed}

For a traditional lubricant-for example, a thick grease in a journal bearing-the friction coefficient strongly depends on the sliding velocity. As the sliding speed increases, more lubricant is entrained into the contact resulting in a pressure in the lubricant that can partially support the external load: This process is known as mixed lubrication. At yet higher sliding speeds, the friction may increase with velocity because the lubricant forms a continuous film that separates the solids and undergoes Newtonian flow: Viscous dissipation within the lubricant is responsible for the friction in the hydrodynamic lubrication regime [32,33].

To investigate the slider-on-ice friction in the context of lubrication, we perform friction experiments at velocities ranging from $1 \mu \mathrm{m} / \mathrm{s}$ to $10 \mathrm{~cm} / \mathrm{s}$ and find a nonmonotonic relation between friction and sliding velocity at a temperature of $-20^{\circ} \mathrm{C}$ [Fig. 5(a), red triangles]. This velocity dependence of the friction can be fully explained using a velocity-dependent ploughing model: During sliding, the slider plastically indents the ice in the normal direction at an indentation speed $v_{\text {ind }}$, which is a fraction of the sliding speed $v_{s}$ (approximately 4\%; see Appendix B). Consequently, the indentation depth sets the ploughing area $A_{P}$, the projected cross-sectional area over which the slider ploughs through the ice. Both during indentation and (subsequent) ploughing, the velocity-dependent penetration hardness of the ice controls the normal and tangential pressure at the interface. Remarkably, the penetration hardness is highly speed dependent; for increasing indentation speed, the penetration hardness increases, as can be seen in the inset of Fig. 2(a) for various temperatures. The hardness of ice for temperatures up to $-25^{\circ} \mathrm{C}$ has been studied before for various loading times when a sphere is pushed into the ice [34-36] and for various impact velocities with a short contact time when a steel sphere is dropped onto the ice $[37,38]$. Although both measurement methods and the definition of hardness vary, an increase of the hardness with decreasing temperature and increasing speed was also observed in these experiments. This observation is in qualitative agreement with our findings for a broad temperature and indentation speed domain. However, the linear dependence of the hardness on temperature in a broad domain from $-110^{\circ} \mathrm{C}$ almost up to melting that we report here, to the best of our knowledge, has not been observed before.

As the velocity domain during ice skating is broad, from standing still up to moving at about $30 \mathrm{~m} / \mathrm{s}$, the velocity dependence of the hardness of the ice is of key importance. Thus far, most calculations of friction on ice used either a 
(a) Plastic regime

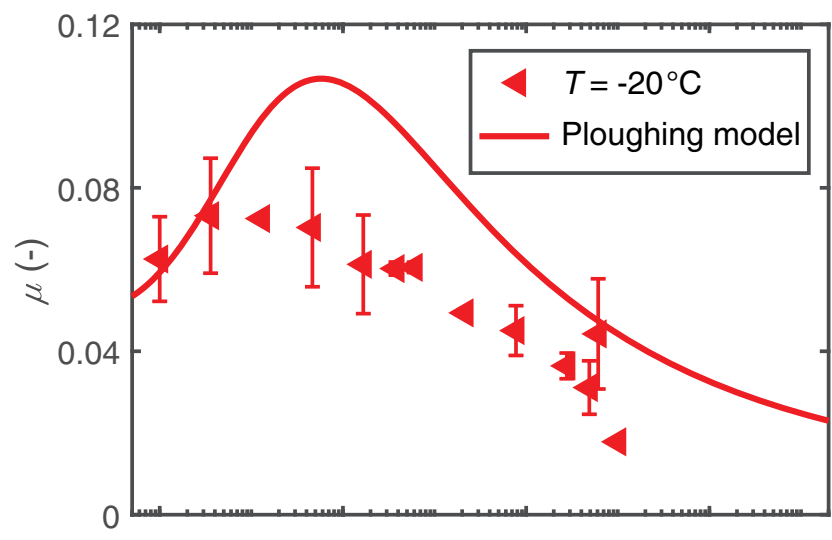

(b) Elastic regime

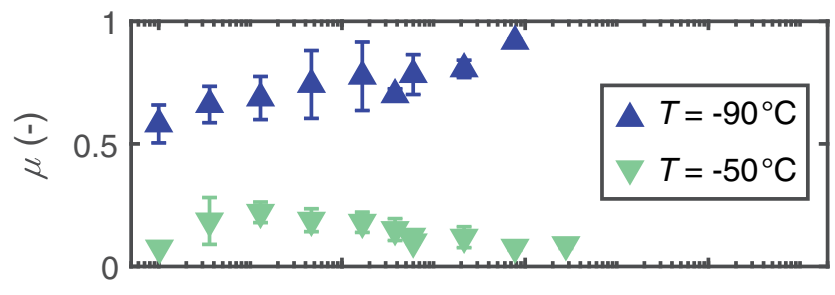

(c) Artificial ice

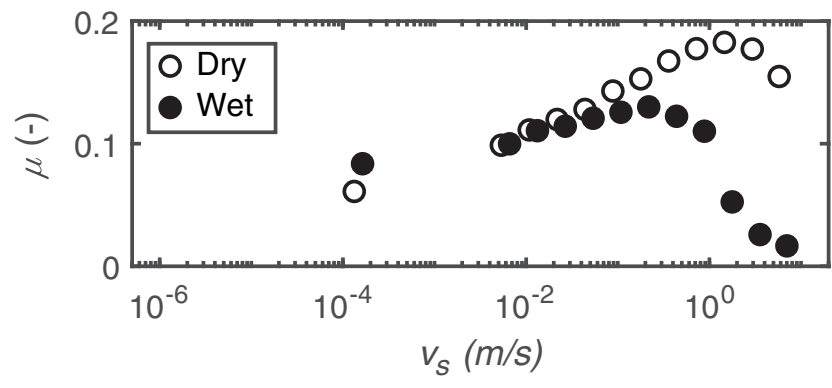

FIG. 5. Friction coefficient $\mu$ as a function of the sliding speed $v_{s}$ for a smooth glass sphere (surface roughness $S_{q}=98 \mathrm{~nm}$ ). All measurements were performed with increasing and decreasing sliding velocity to confirm that hysteresis was absent. (a) At $-20^{\circ} \mathrm{C}$ (red triangles), a nonmonotonic dependence of the friction on the sliding speed is found, which can be understood based on ploughing [Eq. (6), red line]. (b) At $-50^{\circ} \mathrm{C}$ (green triangles) and $-90^{\circ} \mathrm{C}$ (blue triangles), velocity strengthening of the friction is observed, which can be qualitatively described as a result of a stress-augmented thermal process; the stress exerted by the slider at the interface decreases the effective activation barrier, resulting in a logarithmic increase of the stress with the rate or velocity. (c) Dry (open markers) and water-lubricated (solid markers) friction on artificial ice (HDPE) (using the same glass slider) at room temperature and at a normal force of $1 \mathrm{~N}$. The error bars represent the standard deviation in the measured friction force. In panel (c), the error is of the order of the symbol size.

constant or linear dependence of the hardness on velocity [10,39-42]. The ploughing force is set by both the penetration hardness in the normal direction (at $v_{\text {ind }}$ ) and by the penetration hardness in the tangential direction (at $v_{s}$ ). Consequently, we can write, for the friction coefficient,

$$
\mu_{P}=\frac{4 \sqrt{2 N}}{3 \pi^{3 / 2} R} \frac{P_{h}\left(T, v_{\mathrm{s}}\right)}{P_{h}\left(T, v_{\text {ind }}\right)^{3 / 2}} .
$$

For the data shown in Fig. 5(a), with a set sliding speed $v_{s}$, the corresponding indentation speed $v_{\text {ind }}$ for the spherical slider with radius $R$ and average normal force $N$ can be calculated directly (see Appendix B). Therefore, without adjustable parameters, the ploughing contribution can now be calculated for the $-20^{\circ} \mathrm{C}$ data and, as shown with the red line in Fig. 5(a), this calculation is in reasonable agreement with the measured friction coefficient; the ploughing model captures the nonmonotonic dependence of friction on sliding speed.

At $T=-50{ }^{\circ} \mathrm{C}$ and $-90^{\circ} \mathrm{C}$ [Fig. 5(b)], we find velocity dependencies that cannot be described based on ploughing. This result is expected as, at low temperatures, the penetration hardness of the ice increases and the ice can accommodate the normal force through elastic deformations. At $-90{ }^{\circ} \mathrm{C}$ (blue markers in Fig. 5), we observe-in agreement with earlier measurements [14]—velocity strengthening friction; the friction coefficient increases logarithmically from a friction coefficient of $\mu \approx 0.55$ at $\mu \mathrm{m} / \mathrm{s}$ speeds up to $\mu \approx 0.9$ for speeds on the order of $\mathrm{cm} / \mathrm{s}$. A logarithmic increase with speed has been described before for Eyring processes; a stress (or force) can effectively decrease the Arrhenius energy barrier and therefore influence the rate of the process; the Arrhenius process for the ice surface is the diffusive motion of the weakly bonded surface water molecules. In such so-called stress-augmented systems, the relation between the applied stress, or force, and the velocity is logarithmic $[43,44]$, like we observe here. The $-50^{\circ} \mathrm{C}$ case seems to be in between the behavior of the $-20{ }^{\circ} \mathrm{C}$ and the $-90{ }^{\circ} \mathrm{C}$ cases, sharing some of the features of both. A detailed (quantitative) understanding of these observations is not available yet.

\section{E. Substrate}

As the large velocity dependence of ice friction is often attributed to water lubrication, we finally investigate the role of water lubrication in our friction experiments. We replace the ice surface with a material that has similar mechanical properties: high-density polyethylene (HDPE, elastic modulus $1.1 \mathrm{GPa}$, surface roughness of $207 \mathrm{~nm}$; from Simona). In Fig. 5(c), the dry (open circles) and waterlubricated (closed circles) friction coefficients, measured at a normal force of $1 \mathrm{~N}$, are plotted as a function of sliding speed. The significant decrease of the water-lubricated friction coefficient observed at sliding speeds higher than $1 \mathrm{~m} / \mathrm{s}$ indicates the onset of mixed lubrication. At larger sliding speeds, which we cannot reach using our current experimental setup, elastohydrodynamic lubrication is expected to occur. These measurements suggest that, at least up to sliding speeds of $1 \mathrm{~m} / \mathrm{s}$, the slipperiness of ice is not the result of mixed or hydrodynamic lubrication from a liquid water film. However, we note that the onset of mixed 
lubrication can also depend on the surface chemistry and would occur at lower speeds if the contact pressure was reduced.

\section{DISCUSSION AND CONCLUSION}

Altogether, the speed dependence of sliding on ice depends strongly on the contact regime, elastic or plastic deformation. When the contact of the slider on ice is mainly elastic, as observed for low temperatures and smooth spherical sliders, the observed friction can be linked to the mobility of confined water. However, for a plastic contact, the friction is set by the amount of ploughing, which largely depends on the hardness, the slider geometry, and exerted normal force.

One interesting observation that merits discussion is that during ploughing, tracks and debris particles can be formed when the temperatures and contact pressures are high. Under these conditions, the dynamics of ice debris particles are expected to become important, particularly if the sliding motion is reciprocated on a relatively small section of the ice. Indeed, we have observed that when our sphere is made to oscillate over the same surface area (an option that is readily available on the rheometer) at $-5^{\circ} \mathrm{C}$, the frictional response does not a steady state after 2 minutes. This was measured with a smooth glass sphere oscillating at a frequency of $20 \mathrm{~Hz}$, with an amplitude of $100 \mu \mathrm{m}$ and normal force of $2 \mathrm{~N}$.

Another point is that the chemical nature of the slider can be of importance for the frictional behavior. In winter sports, hydrophobic coatings are used to reduce the friction $[8,45]$. Although sliding on snow, which is a soft porous media of ice and water, is very different than sliding on an ice surface, an influence of the wetting properties could be expected. In our study, the sliders (Table I) are all hydrophilic, and this may explain why there is little variation in the friction that was measured with the various materials. In this context, it would be interesting to conduct similar ice friction experiments with hydrophobic materials in the future.

The thermally activated diffusive motion of surface molecules could also be interpreted as a result of the presence of a premelted (quasi)liquid water layer. This liquidlike layer, starting from one bilayer up to $45 \mathrm{~nm}$, grows above a critical temperature, which has been experimentally reported in the range of $-70^{\circ} \mathrm{C}$ up to $-2^{\circ} \mathrm{C}[12,13,46-49]$. However, in the given temperature domain, we measure a continuous decrease of the friction, independent of the presence or thickness of a liquidlike water layer. Therefore, we interpret the measured Arrhenius behavior of the friction coefficient as a result of ice-surface diffusion.

In the mid-20th century, frictional melting of the ice was already suggested as an explanation for the slipperiness of ice [3]. The heat locally generates a lubricating water film that, with increasing sliding velocity, eventually results in a full water film that separates the surfaces (aquaplaning). We observe that ice remains highly slippery at speeds as low as $1 \mu \mathrm{m} / \mathrm{s}$ for $-20^{\circ} \mathrm{C}$; therefore, ice remains slippery down to very low sliding speeds, where the rate at which energy is injected into the interface becomes negligible compared to that at higher sliding speeds. This result indicates that the friction coefficient is not very sensitive to frictional heating. We interpret that, for the given microsurface and macrosurface geometry, the slipperiness up to a speed of at least $1 \mathrm{~m} / \mathrm{s}$ is not the result of mixed or hydrodynamic lubrication. Additionally, the slipperiness does not vary significantly when a silicon carbide or a glass slider is used, although the thermal conductivity of these materials differs by 2 orders of magnitude.

In summary, temperature, pressure, and speed each have an important impact on ice friction, largely through the hardness of the ice. This hardness increases with decreasing temperature and increasing strain rate (indentation speed). On the other hand, the contact pressure exerted at the slideron-ice interface is set by the slider topography and geometry. When this contact pressure approaches the ice hardness, ploughing friction becomes dominant. This ploughing friction depends on the sliding speed because the rate at which the slider indents the ice in the normal direction and ploughs through the ice in the tangential direction varies with the sliding speed and the speeddependent hardness. Alternatively, at contact pressures significantly below the ice hardness, no ploughing occurs, and the friction is adhesive in nature. In this elastic regime, ice friction is low and set by the mobility of the confined water at the slider-on-ice interface. Ice friction in this regime is inversely proportional to the mobility of water molecules at the free ice surface, which can be viewed as an activated process with an Arrhenius temperature dependence. Increasing the local contact pressure exerted at the slider-on-ice interface leads to increased confinement and an exponential increase in interfacial shear stress.

Ice friction is thus low due to the high mobility of the water molecules at the slider-on-ice interface at temperatures close to the ice melting point. This slipperiness can be suppressed by increasing the local contact pressure towards the ice hardness. It is the exceptionally high hardness of ice, close to its melting point, that enables the slipperiness of ice and distinguishes ice from other solids. In practice, this means that the optimal ice skate is very smooth and has sharp edges. When the smooth surface makes contact with the ice, the contact pressure, and therefore the sliding friction, is low. When the skate is tilted, the sharp edge plastically penetrates the ice, leading to high ploughing friction that enables grip, which is necessary to accelerate and turn.

\section{ACKNOWLEDGMENTS}

R. W. L. thanks Shell for financial support (PT 67354). B.W. acknowledges funding from the Netherlands 
Organization for Scientific Research (NWO) VENI Grant No. VI.Veni.192.177.

\section{APPENDIX A: QUANTIFICATION AND FIT OF THE PENETRATION OF ICE}

The penetration hardness $P_{h}$ is quantified with an indentation test, where a sphere is pushed into the ice surface. The indentation depth $\delta$ as a function of the force $N$ is monitored as shown in Fig. 6 for several temperatures. As discussed in Sec. II of the main text, the penetration and error can be calculated based on the slope of these graphs:

$$
\frac{\Delta \delta}{\Delta N}=\frac{1}{2 \pi R P_{h}},
$$

with $R=1.6 \mathrm{~mm}$ the radius of the indenter. The penetration hardness is fitted with a polynomial regression on the variables temperature $T$ (in ${ }^{\circ} \mathrm{C}$ ) and the logarithm of the indentation speed $\ln \left(v_{\text {ind }}\right)$ with, respectively, 1 and 3 degrees:

$$
\begin{aligned}
P_{h}\left(T, v_{\text {ind }}\right)= & P_{00}+P_{10} T+P_{01} \ln \left(v_{\text {ind }}\right) \\
& +P_{11} T \ln \left(v_{\text {ind }}\right)+P_{02} \ln \left(v_{\text {ind }}\right)^{2} \\
& +P_{12} T \ln \left(v_{\text {ind }}\right)^{2}+P_{03} \ln \left(v_{\text {ind }}\right)^{3} .
\end{aligned}
$$

The fit parameters found, with a resulting coefficient of determination of $R^{2}=0.8885$, are $P_{00}=8.041 \times 10^{8}$,

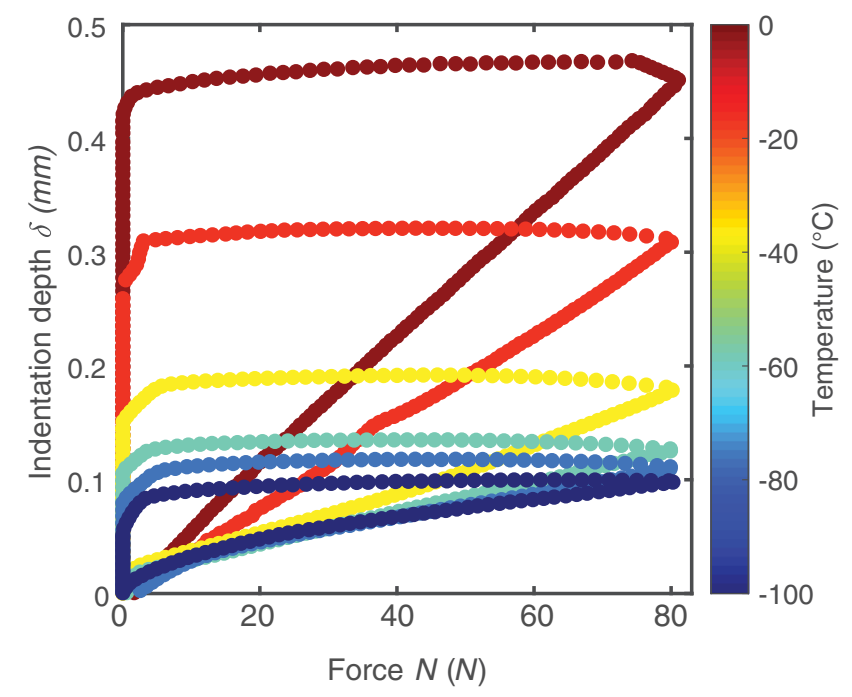

FIG. 6. Indentation depth $\delta$ as a function of the force $N$ for an indentation speed of $3.8 \mu \mathrm{m} / \mathrm{s}$ captured with a hardness test for various temperatures. A plastic, irreversible, loading curve is observed; after indenting up to a maximum force of $80 \mathrm{~N}$, during retraction the force quickly drops. During loading, the indentation increases linearly with the indentation force, where the slope $\Delta \delta / \Delta N$ is inversely related to the penetration hardness. For increasing temperature, we observe a larger slope and therefore a lower penetration hardness.
$P_{10}=-3.337 \times 10^{6}, P_{01}=1.465 \times 10^{8}, P_{11}=-2.645 \times 10^{5}$, $P_{02}=8.936 \times 10^{6}, \quad P_{12}=-6.282 \times 10^{3}, \quad$ and $P_{03}=$ $1.792 \times 10^{5}$. For a constant indentation speed of $v_{\text {ind }}=3.8 \mu \mathrm{m} / \mathrm{s}$, as used in Figs. 2(a) and 6, this fit results in a penetration hardness that linearly decreases with temperature as $P_{h}=(-1.01 T+19.2) \times 10^{6}$.

Close to the melting point, pressure melting occurs; the melting temperature of ice decreases with increasing pressure because the liquid-phase density is lower than the solid phase. The pressure that has to be exceeded to melt ice is described by the Clausius-Clapeyron equation [50]:

$$
P_{m}=\frac{L}{T_{0} \Delta V} T=-13.5 \times 10^{6} T,
$$

with $L=3.34 \times 10^{5} \mathrm{~J} / \mathrm{kg}$ the latent heat of fusion, $T_{0}=0^{\circ}$ $\mathrm{C}$ the freezing point of water at a pressure of $1 \mathrm{bar}$, and $\Delta V=-9.05 \times 10^{-5} \mathrm{~m}^{3} / \mathrm{kg}$ the change in specific volume from solid to liquid. For temperatures higher than $-1.5^{\circ} \mathrm{C}$, the pressure necessary for pressure melting is lower than the penetration hardness. Therefore, the limiting pressure for $-1.5^{\circ} \mathrm{C}$ up to $0{ }^{\circ} \mathrm{C}$ in Fig. 2(a) is described by the ClausiusClapeyron equation.

\section{APPENDIX B: PLOUGHING MODEL}

When sliding a sphere on ice, ploughing will occur when the contact pressure exceeds the penetration hardness. In this plastic regime, the sphere indents into the ice up to the contact area $A_{c}$ can support the normal force: $A_{C}=\left[N / P_{h}(T)\right]$. This contact area, the projected area of contact in the normal direction, which is in contact with the ice surface, is $A_{c}=\frac{1}{2} \pi r^{2}$, with $r$ the radius of the ploughing track. The final depth of indentation $\delta$ can be written, with the use of $\delta \approx\left(r^{2} / 2 R\right)$ for $\delta \ll R$, as $\delta=\left[N / \pi R P_{h}(T)\right]$. Consequently, this indentation results in scratching ice with a ploughing area $A_{P}$ and a ploughing force $F_{P}=A_{P} P_{h}(T)$. The ploughing area is the cross-sectional area $A_{P} \approx \frac{4}{3} r \delta$, and it can be rewritten as

$$
A_{P}=\frac{4 \sqrt{2}}{3 \pi^{3 / 2} R} \frac{N^{3 / 2}}{P_{h}(T)^{3 / 2}},
$$

which results in a ploughing force of

$$
F_{P}=\frac{4 \sqrt{2}}{3 \pi^{3 / 2} R} \frac{N^{3 / 2}}{\sqrt{P_{h}(T)}} .
$$

With $\mu_{P}=F_{P} / N$, we get Eq. (3).

\section{Velocity-dependent ploughing model}

To take into account the velocity dependency of the penetration hardness, as is shown in the inset of Fig. 2(a) and fitted with Eq. (A2), the ploughing model has to be 


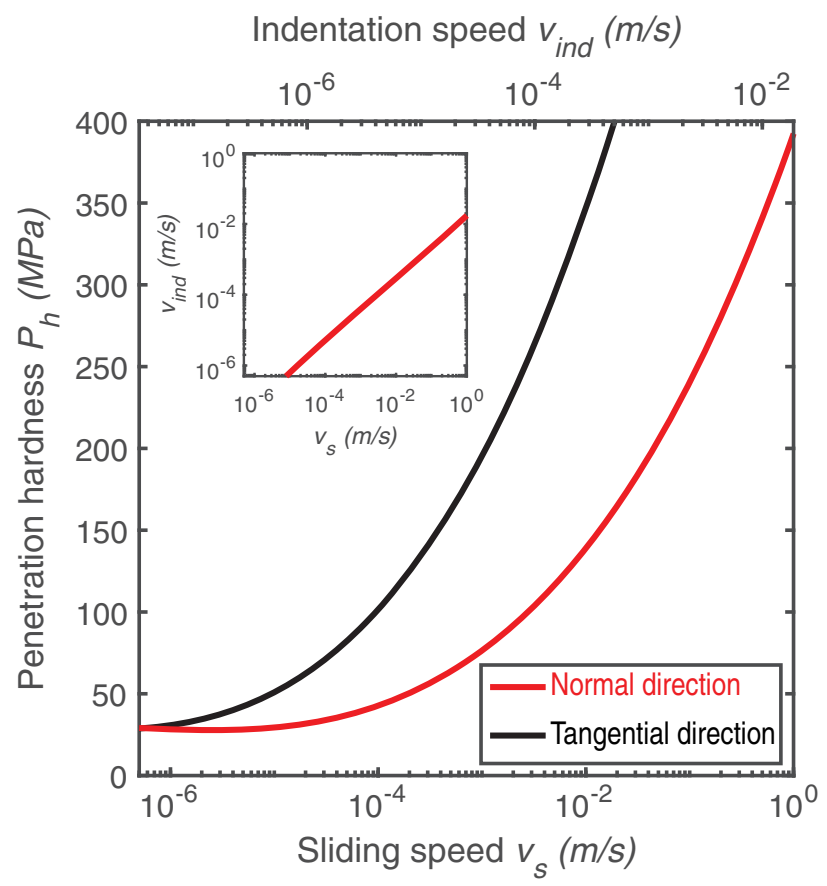

FIG. 7. Penetration hardness in the normal direction (red) and tangential direction (black) as a function of sliding speed for ice at a temperature of $-20^{\circ} \mathrm{C}$ based on Eq. (A2). The calculated indentation speed corresponding to the set sliding speed is given in the inset and as top axes for sliding a glass sphere $(R=1.84 \mathrm{~mm})$ at a normal force of $2.5 \mathrm{~N}$ over ice at $-20^{\circ} \mathrm{C}$, Eq. (B5). The indentation speed is around $4 \%$ of the sliding speed, and consequently, the penetration hardness in the normal direction is smaller than the penetration hardness in the tangential direction.

modified. Two velocities, and therefore two penetration hardnesses, are involved in ploughing: the indentation speed $v_{\text {ind }}$ in the normal direction, where the ice is indented by the slider; and the sliding speed $v_{s}$ in the tangential direction, the speed at which the final ploughing occurs. As the ploughing area $A_{P}$ is set by the indentation in the normal direction, the corresponding penetration hardness is at the indentation speed:

$$
A_{P}=\frac{4 \sqrt{2}}{3 \pi^{3 / 2} R} \frac{N^{3 / 2}}{P_{h}\left(T, v_{\text {ind }}\right)^{3 / 2}} .
$$

The subsequent ploughing force is then based on the penetration hardness at the sliding speed and the calculated ploughing area $A_{P}$ :

$$
F_{P}=\frac{4 \sqrt{2}}{3 \pi^{3 / 2} R} \frac{P_{h}\left(T, v_{s}\right)}{P_{h}\left(T, v_{\text {ind }}\right)^{3 / 2}} N^{3 / 2} .
$$

Based on the sphere-on-ice geometry, we can calculate the indentation speed corresponding to the sliding speed and subsequently calculate the related penetration hardness for the ploughing force. The ratio of the related speeds is

$$
\frac{v_{\text {ind }}}{v_{s}}=\frac{\delta}{r}=\sqrt{\frac{N}{2 \pi R^{2} P_{h}\left(T, v_{\text {ind }}\right)}} .
$$

This nonlinear equation can be numerically solved to yield an indentation speed $v_{\text {ind }}$ for a given sliding speed $v_{s}$. For a glass sphere sliding over ice at $-20^{\circ} \mathrm{C}$, the resulting indentation speed as a function of the sliding speed is given in the inset of Fig. 7; the indentation speed is, in general, a fraction of the sliding speed, around $4 \%$. Consequently, for a given sliding speed, we can calculate the penetration hardness in the normal and tangential directions; see Fig. 7. Finally, the friction force and friction coefficient can be calculated based on Eq. (B4), where the indentation speed is based on numerically solving Eq. (B5).

\section{APPENDIX C: CONTACT MECHANICS}

To quantify the real contact area (RCA) and the average contact pressure $P_{c}$ of the spherical sliders on ice, we use the Tribology Simulator (from Tribonet [17]). Based on the surface topography of the slider and the mechanical properties of the slider and the ice surface, the simulator

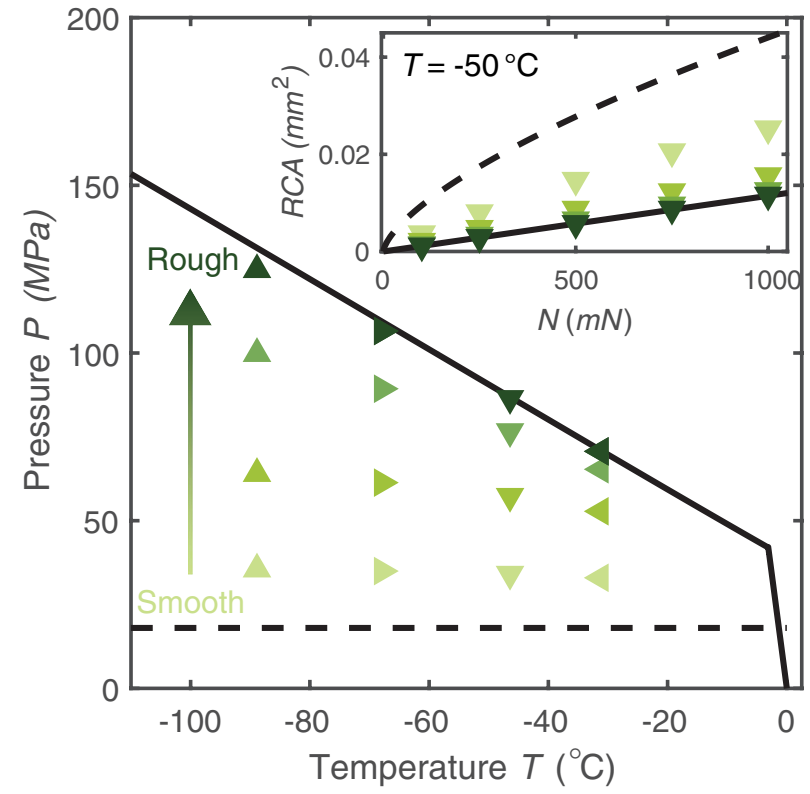

FIG. 8. Pressure $P$ as function of the temperature $T$ for glass spheres with surface roughnesses $98,222,575$, and $3077 \mathrm{~nm}$ at a normal force of $500 \mathrm{mN}$. The smoothest sphere is mainly elastic where, for increasing surface roughnesses, the pressure increases until the plastic limit is reached. The dashed and solid lines are, respectively, the elastic Hertzian pressure and the penetration hardness $P_{h}$ of the ice. For the latter, the penetration hardness in the normal direction for the set sliding speed of $0.38 \mathrm{~mm} / \mathrm{s}$ is used. Inset: RCA as a function of the normal force $N$. Independent of the surface roughness, the real contact area increases linearly with the normal force. Therefore, the contact pressure is almost independent of the normal force. 
solves the elastic-plastic contact equations through a numerical model.

The plastic limit is set by the penetration hardness of the ice in the normal direction, calculated for the set sliding speed $v_{s}=0.38 \mathrm{~mm} / \mathrm{s}$ and temperature $T$, with the use of Eqs. (A2) and (B5). In Fig. 8, the contact pressure as a function of temperature is given for glass spheres with surface roughness $S_{q}$ from $98 \mathrm{~nm}$ to $3077 \mathrm{~nm}$. The dashed and solid lines represent, respectively, the elastic Hertzian contact pressure [51] and the plastic limit given by the penetration hardness as $N / P_{h}$. For increasing surface roughnesses, the contact mechanics convert from a mainly elastic contact to a plastic contact. The RCA increases linearly, even for the relatively smooth sphere, with the normal force, as is given in the inset of Fig. 8. Therefore, the contact pressure is almost independent of the normal force.

In Fig. 9, the real contact area for the $\mathrm{SiC}$ spheres is given as a function of the normal force. Both spheres, with radii of 6.00 (red) and $0.75 \mathrm{~mm}$ (blue), have a mainly elastic contact with the ice surface at $-50{ }^{\circ} \mathrm{C}$ (open circles) and at $-90^{\circ} \mathrm{C}$ (closed circles). The large sphere has a large RCA and, due to the finite size of the measured surface topography ( 208 by $208 \mu \mathrm{m}$ ), can only be calculated up to $400 \mathrm{mN}$.

The contact mechanics for a sapphire sphere on ice are given in Fig. 10. The contact is mainly elastic due to the low

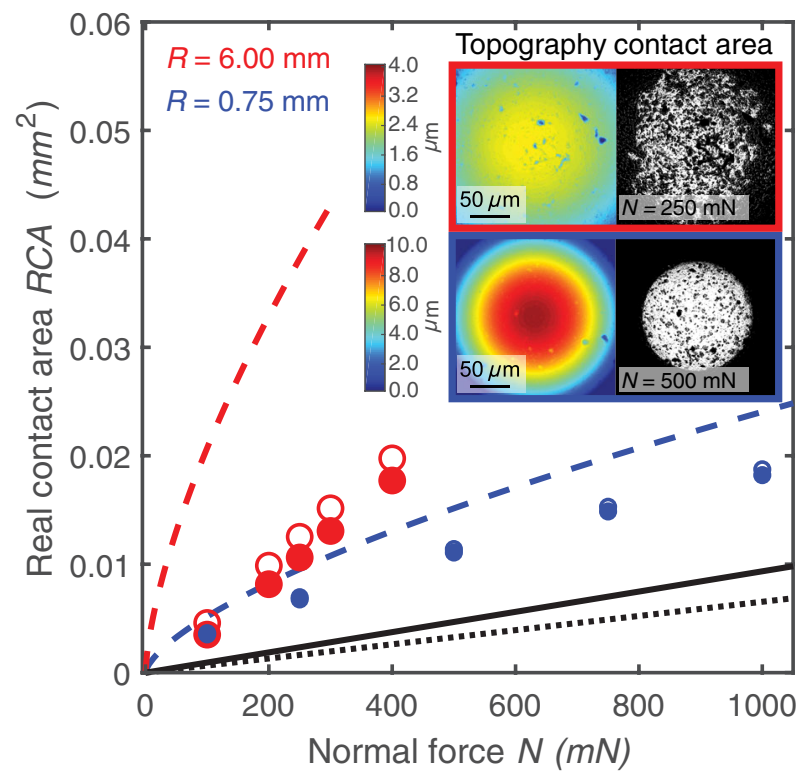

FIG. 9. Contact mechanics of the $\mathrm{SiC}$ spheres sliding on ice and RCA as a function of normal force $N$ for a sphere with a radius of $6.00 \mathrm{~mm}$ (red) and $0.75 \mathrm{~mm}$ (blue) at temperatures of $-50^{\circ} \mathrm{C}$ (open circles) and $-90^{\circ} \mathrm{C}$ (closed circles). The dashed lines represent the elastic Hertzian pressure. The solid and dotted lines are, respectively, the plastic limit set by the penetration hardness at temperatures of $-50{ }^{\circ} \mathrm{C}$ and $-90^{\circ} \mathrm{C}$. Inset: surface topography (left) and calculated area of real contact (right) for the $\mathrm{SiC}$ spheres.

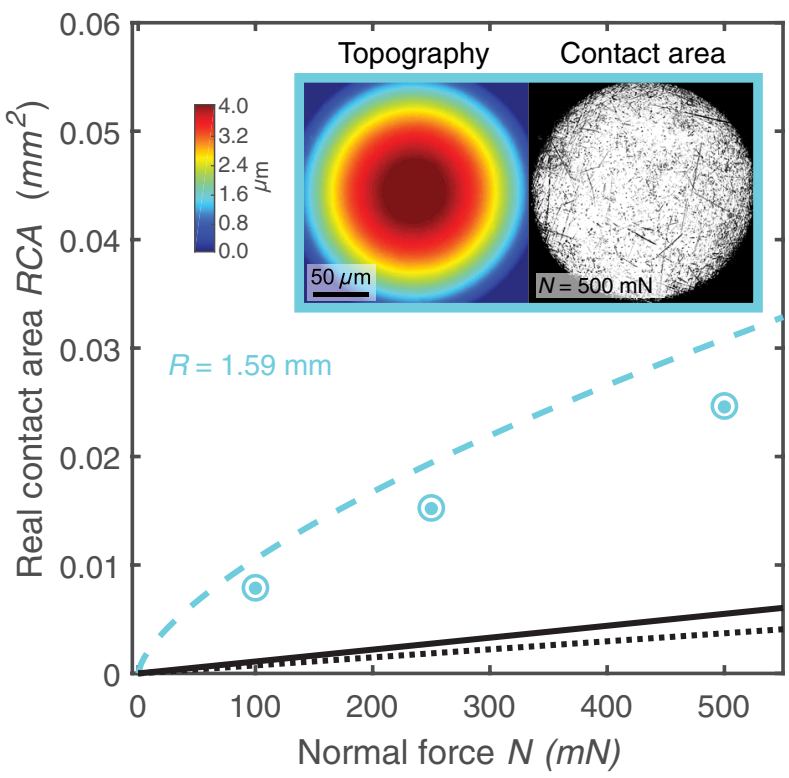

FIG. 10. Contact mechanics of a sapphire sphere (radius of $1.59 \mathrm{~mm}$ ) sliding on ice and RCA as a function of the normal force $\mathrm{N}$ at temperatures of $-50{ }^{\circ} \mathrm{C}$ (open circles) and $-90{ }^{\circ} \mathrm{C}$ (closed circles). The dashed line represents the elastic Hertzian pressure, and the solid and dotted lines are, respectively, the plastic limit set by the penetration hardness at temperatures of $-50{ }^{\circ} \mathrm{C}$ and $-90^{\circ} \mathrm{C}$. Inset: surface topography (left) and calculated area of real contact (right) for the sapphire sphere.

surface roughness $\left(S_{q}=28 \mathrm{~nm}\right)$. Therefore, the RCA increases, as expected for an elastic Hertzian contact [51], sublinearly with the normal force. The RCA for a normal force of $500 \mathrm{mN}$ is used to quantify the shear stress and contact pressure.

\section{APPENDIX D: CONTRIBUTION OF PLOUGHING ON THE MICROROUGHNESS SCALE}

Ploughing not only occurs on the macroscale of the slider-on-ice contact; single asperities can plastically deform the ice and therefore plough through it tangentially. In Fig. 3(b), the ploughing tracks that were left on the ice after a sphere slid over the ice surface are given. For a high surface roughness, $S_{q}=3077 \mathrm{~nm}$, the measured ploughing area $\left(A_{P}=7.8 \times 10^{-11} \mathrm{~m}^{2}\right)$ results in a friction coefficient based on ploughing of $\mu_{P}=0.07$ [for $N=0.21 \mathrm{~N}$, penetration hardness in the normal direction $P_{h}=194 \mathrm{MPa}$ and using Eq. (2)]. As the increase in the friction coefficient for the highest surface roughness relative to the lowest surface roughness is $\Delta \mu=0.24$, the ploughing can only explain $30 \%$ of the increased friction. Based on the measured surface topography, a ploughing area of $\left(A_{P}=12.2 \times 10^{-11} \mathrm{~m}^{2}\right)$ can be calculated [see gray area in the top panel of Fig. 3(b)]. As the orientation of the sphere on ice is not the same, a small difference is found compared with the measurements in both the ploughing 


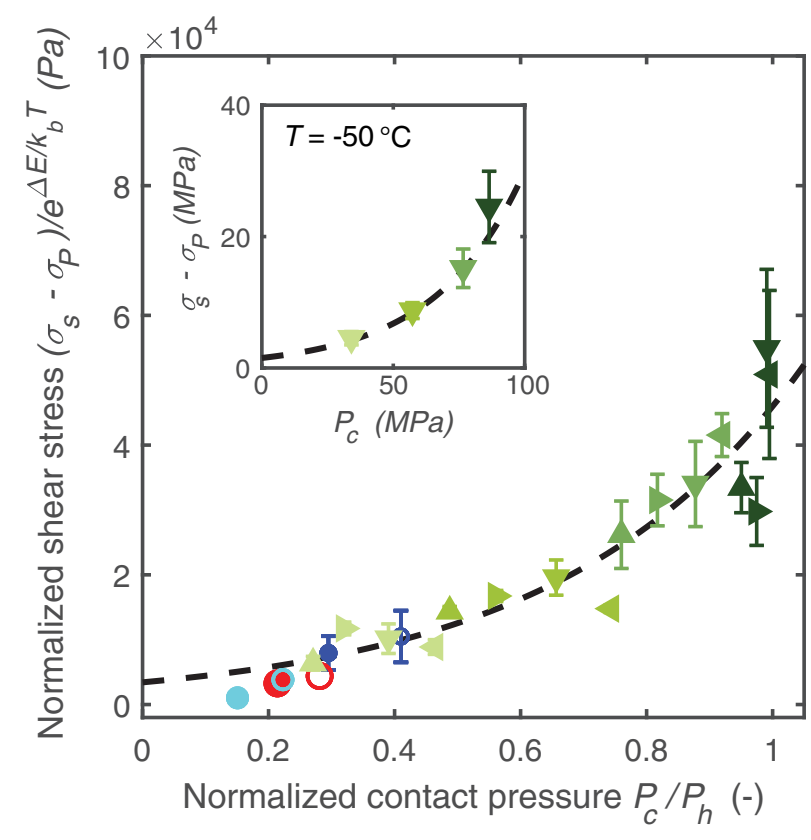

FIG. 11. Normalized effective shear stress $\left(\sigma_{s}-\sigma_{P}\right) / e^{\Delta E / k_{B} T}$ as a function of the normalized contact pressure $P_{c} / P_{h}$ for various sliders, surface roughnesses, and temperatures at a sliding speed of $0.38 \mathrm{~mm} / \mathrm{s}$. Here, the effective shear stress is based on the measured friction force, excluding the ploughing contribution. The plastic indentation of the sphere in the ice surface, mainly for high surface roughnesses, results in a ploughing area $A_{P}$ and ploughing force $F_{P}=A_{P} P_{h}$ [Eq. (2)]. The ploughing can explain up to $40 \%$ of the observed increased friction. The dashed line is a fit using Eq. (5). The same symbols and colors are used as in Fig. 4. Inset: effective shear stress $\sigma_{s}-\sigma_{P}$ as a function of the contact pressure $P_{c}$ for various glass sliders with increasing surface roughness at $T=-50{ }^{\circ} \mathrm{C}$ and a sliding speed of $0.38 \mathrm{~mm} / \mathrm{s}$.

track and the ploughing area. Now, the ploughing can explain $40 \%$ of the observed increased friction.

In Fig. 11, the increase of shear stress with increasing contact pressure where the ploughing is excluded is given. For the ploughing stress $\sigma_{P}=F_{P} / \mathrm{RCA}$, a ploughing force based on the quantified plastic indentation of the surface topography is used. We can model the effective shear stress $\sigma_{s}-\sigma_{P}$ as Eq. (5) with $\sigma_{0}=3.4 \mathrm{kPa}$ and $b=2.6$. Consequently, if ploughing is taken into account, the shear stress set by the mobility of the ice surface is, although smaller, still the main contribution to the friction force.

[1] R. Rosenberg, Why Is Ice Slippery?, Phys. Today 58, No. 12, 50 (2005).

[2] J. Joly, The Phenomena of Skating, Sci. Proc. R. Soc. 5, 453 (1886).

[3] F. P. Bowden and T. Hughes, The Mechanism of Sliding on Ice and Snow, Proc. R. Soc. A 172, 280 (1939).

[4] P. Faraday, XXIV. On Regelation, and on the Conservation of Force, Philos. Mag. 17, 162 (1859).
[5] S. Colbeck, The Kinetic Friction of Snow, J. Glaciol. 34, 78 (1988).

[6] J. J. de Koning, G. De Groot, and G. J. van Ingen Schenau, Ice Friction During Speed Skating, J. Biomechanics 25, 565 (1992).

[7] A.-M. Kietzig, S. G. Hatzikiriakos, and P. Englezos, Ice Friction: The Effects of Surface Roughness, Structure, and Hydrophobicity, J. Appl. Phys. 106, 024303 (2009).

[8] A.-M. Kietzig, S. G. Hatzikiriakos, and P. Englezos, Physics of Ice Friction, J. Appl. Phys. 107, 081101 (2010).

[9] A. Spagni, A. Berardo, D. Marchetto, E. Gualtieri, N. M. Pugno, and S. Valeri, Friction of Rough Surfaces on Ice: Experiments and Modeling, Wear 368, 258 (2016).

[10] J. van Leeuwen, Skating on Slippery Ice, SciPost Phys. 3, 042 (2017).

[11] M. Ovaska and A. J. Tuononen, Multiscale Imaging of Wear Tracks in Ice Skate Friction, Tribol. Int. 121, 280 (2018).

[12] B. Slater and A. Michaelides, Surface Premelting of Water Ice, Nat. Rev. Chem. 3, 172 (2019).

[13] Y. Nagata, T. Hama, E. H. Backus, M. Mezger, D. Bonn, M. Bonn, and G. Sazaki, The Surface of Ice under Equilibrium and Nonequilibrium Conditions, Acc. Chem. Res. 52, 1006 (2019).

[14] B. Weber, Y. Nagata, S. Ketzetzi, F. Tang, W. J. Smit, H. J. Bakker, E. H. Backus, M. Bonn, and D. Bonn, Molecular Insight into the Slipperiness of Ice, J. Phys. Chem. Lett. 9, 2838 (2018).

[15] F.-C. Hsia, F. M. Elam, D. Bonn, B. Weber, and S. E. Franklin, Wear Particle Dynamics Drive the Difference between Repeated and Non-repeated Reciprocated Sliding, Tribol. Int. 142, 105983 (2020).

[16] L. Canale, J. Comtet, A. Niguès, C. Cohen, C. Clanet, A. Siria, and L. Bocquet, Nanorheology of Interfacial Water During Ice Gliding, Phys. Rev. X 9, 041025 (2019).

[17] See https://www.tribonet.org.

[18] W. Kingery, Regelation, Surface Diffusion, and Ice Sintering, J. Appl. Phys. 31, 833 (1960).

[19] I. Gladich, W. Pfalzgraff, O. Maršálek, P. Jungwirth, M. Roeselová, and S. Neshyba, Arrhenius Analysis of Anisotropic Surface Diffusion on the Prismatic Facet of Ice, Phys. Chem. Chem. Phys. 13, 19960 (2011).

[20] K. Tusima, Friction of a Steel Ball on a Single Crystal of Ice, J. Glaciol. 19, 225 (1977).

[21] F. Bowden, A. Moore, and D. Tabor, The Ploughing and Adhesion of Sliding Metals, J. Appl. Phys. 14, 80 (1943).

[22] R. Spurr, The "Ploughing" Contribution to Friction, Br. J. Appl. Phys. 7, 260 (1956).

[23] R. Liefferink, B. Weber, and D. Bonn, Ploughing Friction on Wet and Dry Sand, Phys. Rev. E 98, 052903 (2018).

[24] M. Denny, Gliding for Gold: The Physics of Winter Sports (The Johns Hopkins University Press, Baltimore, 2011), https://jhupbooks.press.jhu.edu/title/gliding-gold.

[25] J. van Leeuwen, The Friction of Tilted Skates on Ice, SciPost Phys. 8, 059 (2020).

[26] B. N. Persson, Theory of Rubber Friction and Contact Mechanics, J. Chem. Phys. 115, 3840 (2001).

[27] C. Barus, Isothermals, Isopiestics and Isometrics Relative to Viscosity, Am. J. Sci. 45, 87 (1893). 
[28] S. Bair and P. Kottke, Pressure-Viscosity Relationships for Elastohydrodynamics, Tribol. Trans. 46, 289 (2003).

[29] R. Major, J. Houston, M. McGrath, J. Siepmann, and X.-Y. Zhu, Viscous Water Meniscus under Nanoconfinement, Phys. Rev. Lett. 96, 177803 (2006).

[30] J. Gao, R. Szoszkiewicz, U. Landman, E. Riedo et al., Structured and Viscous Water in Subnanometer Gaps, Phys. Rev. B 75, 115415 (2007).

[31] D. Ortiz-Young, H.-C. Chiu, S. Kim, K. Voïtchovsky, and E. Riedo, The Interplay between Apparent Viscosity and Wettability in Nanoconfined Water, Nat. Commun. 4, 2482 (2013).

[32] B. Jacobson, The Stribeck Memorial Lecture, Tribol. Int. 36, 781 (2003).

[33] M. D. Hersey, The Laws of Lubrication of Horizontal Journal Bearings, J. Wash. Acad. Sci. 4, 542 (1914).

[34] T. Butkovich, Hardness of Single Ice Crystals, Am. Mineral. 43, 48 (1958).

[35] P. Barnes and D. Tabor, Plastic Flow and Pressure Melting in the Deformation of Ice I, Nature (London) 210, 878 (1966).

[36] P. Barnes, D. Tabor, and J. Walker, The Friction and Creep of Polycrystalline Ice, Proc. R. Soc. A 324, 127 (1971).

[37] J. Schaefer, R. Ettema, and W. Nixon, Measurements of Icing Hardness, Cold Reg. Sci. Technol. 17, 89 (1989).

[38] L. Poirier, E. P. Lozowski, and R. I. Thompson, Ice Hardness in Winter Sports, Cold Reg. Sci. Technol. 67, 129 (2011).

[39] E. Lozowski, K. Szilder, and S. Maw, A Model of Ice Friction for a Speed Skate Blade, Sports Eng. 16, 239 (2013).

[40] L. Makkonen and M. Tikanmäki, Modeling the Friction of Ice, Cold Reg. Sci. Technol. 102, 84 (2014).
[41] B. Persson, Ice Friction: Role of Non-uniform Frictional Heating and Ice Premelting, J. Chem. Phys. 143, 224701 (2015).

[42] A. J. Tuononen, A. Kriston, and B. Persson, Multiscale Physics of Rubber-Ice Friction, J. Chem. Phys. 145, 114703 (2016).

[43] H. Spikes, Stress-Augmented Thermal Activation: Tribology Feels the Force, Friction and wear in machinery 6, 1 (2018).

[44] T. D. Jacobs and R. W. Carpick, Nanoscale Wear as a Stress-Assisted Chemical Reaction, Nat. Nanotechnol. 8, 108 (2013).

[45] S. C. Colbeck, A Review of the Friction of Snow Skis, Journal of sports sciences 12, 285 (1994).

[46] A. Döppenschmidt and H.-J. Butt, Measuring the Thickness of the Liquid-like Layer on Ice Surfaces with Atomic Force Microscopy, Langmuir 16, 6709 (2000).

[47] H. Bluhm, D. F. Ogletree, C. S. Fadley, Z. Hussain, and M. Salmeron, The Premelting of Ice Studied with Photoelectron Spectroscopy, J. Phys. Condens. Matter 14, L227 (2002).

[48] K.-i. Murata, H. Asakawa, K. Nagashima, Y. Furukawa, and G. Sazaki, Thermodynamic Origin of Surface Melting on Ice Crystals, Proc. Natl. Acad. Sci. U.S.A. 113, E6741 (2016).

[49] M. A. Sánchez, T. Kling, T. Ishiyama, M.-J. van Zadel, P. J. Bisson, M. Mezger, M. N. Jochum, J. D. Cyran, W. J. Smit, H. J. Bakker et al., Experimental and Theoretical Evidence for Bilayer-by-Bilayer Surface Melting of Crystalline Ice, Proc. Natl. Acad. Sci. U.S.A. 114, 227 (2017).

[50] D. V. Schroeder, An Introduction to Thermal Physics (1999), pp. 1284-1285, https://doi.org/10.1119/1.19116.

[51] K. Johnson, Contact Mechanics (Cambridge University, Cambridge, England, 1985), p. 365. 